\title{
Experiences and results from interdisciplinary collaboration: Utilizing qualitative information to formulate disaster risk reduction measures for coastal regions
}

\author{
Grit Martinez ${ }^{\mathrm{a},{ }^{*}}$, Clara Armaroli ${ }^{\mathrm{b}}$, Susana Costas $^{\mathrm{c}}$, Mitchell D. Harley ${ }^{\mathrm{d}}$, Michael Paolisso ${ }^{\mathrm{e}}$

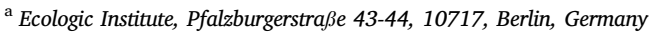 \\ b Dipartimento di Fisica e Scienze della Terra, University of Ferrara, Via Saragat, 1, 44122, Ferrara, Italy \\ c Centro de Investigação Marinha e Ambiental (CIMA), Universidade do Algarve, 8005-139, Faro, Portugal \\ ${ }^{\mathrm{d}}$ Water Research Laboratory, School of Civil and Environmental Engineering, UNSW Sydney, 110 King Street, Manly Vale, NSW, 2093, Australia \\ ${ }^{\mathrm{e}}$ Department of Anthropology, University of Maryland, 4302 Chapel Lane, College Park, MD, 20742, USA
}

\section{A R T I C L E I N F O}

\section{Keywords:}

Interdisciplinarity

Transdisciplinarity

Social science and humanities

Natural science and engineering

Disaster risk reduction

Risk management

Risk perception

Culture

Values

EU floods directive

Porto Garibaldi

Ria Formosa

Coastal zones

\begin{abstract}
A B S T R A C T
This paper illustrates both the potential and challenges of interdisciplinary collaboration amongst researchers from the social sciences/humanities and the natural sciences/engineering in formulating disaster risk reduction measures for coastal regions. The authors aim to share their experiences of working across different scientific and engineering disciplines in the EU project RISC-KIT to co-produce disaster risk reduction measures suitable for specific regional and local contexts, in this case two coastal study areas in Europe (Porto Garibaldi, Italy and Rio Formosa, Portugal).

An overview of the historic-cultural origins of scientific disciplines is first presented, explaining the historical fragmentation of scientific knowledge into natural and social sciences and its associated challenges for prior disaster risk studies - and how the current state of an interdisciplinary approach has emerged. This is followed by an analysis of interdisciplinary collaboration, drawing on the experience and data collected (both quantitative and qualitative) from the two case study areas. The article concludes with suggestions to further overcome the segregation of disciplines within disaster risk studies and projects.

The authors found that qualitative data help to understand knowledge, values and behaviours of institutional and non-institutional stakeholders in formulating appropriate risk reduction measures to increase resilience in a local context - and that such data work "hand in hand" with quantitative information. Furthermore, the collection of qualitative data by researchers of the natural science and engineering disciplines has the potential to build bridges between disciplines and to stimulate further investigations, as in this case, to explain contradictions in human behaviour when managing risk.
\end{abstract}

\section{Introduction}

\subsection{History of disciplinary work in science}

Even today, the works of the universal genius, Leonardo da Vinci, provide an esteemed example of holistic scientific studies that embrace both natural and societal processes (Bermosa, 2017). In this regard, he was succeeded by other scientists such as Philipp Melanchthon, Gottfried Wilhelm Leibniz, Isaac Newton, Johann Wolfgang von Goethe or Alexander von Humboldt, all of whom followed with attempts to fully integrate the phenomena of the world around them in their subsequent studies.

With the dramatic increase of scientific knowledge by the 19th century, more complex fields of study arose. This resulted in a process of disintegration of knowledge and the establishment of scientific disciplines. Broadly speaking, two strands of expertise arose: one focusing on the phenomena of the bio-physical world, mostly understood through collection and analysis of quantifiable data (generally categorized as natural science), and another strand dealing with the non-physical environment, mostly utilizing qualitative data for the analysis of social human issues (generally categorized as social science and humanities). Pioneering discoveries in the fields of physics, medicine, biology and

\footnotetext{
* Corresponding author.

E-mail address: grit.martinez@ecologic.eu (G. Martinez).
} 
chemistry since the late 19th contributed to this increase of 'scientification' often identified with the quantification of bio-physical worlds and living environments.

\subsection{The challenge of interdisciplinary work in disaster risk reduction}

By 1975, the capability of countries such as the United States to resist natural disasters had already been assessed. It was found that "research on disasters was dominated by physical scientists and engineers and that little attempt had been made to tap into social sciences to better understand the economic, social, and political dimensions of extreme natural events" (Mileti and Noji, 1999). Since then, criticism with regards to the narrow approaches taken to disaster risk studies and the exclusion of the human relationship with the natural environment in this process has continued to grow. For instance, David Alexander, an expert in the field of interdisciplinary disaster risk reduction (DRR) studies "who deals with about 800 unpublished manuscripts a year in the field" (Alexander, 2017) observes that "disciplinary barriers have impeded progress towards a better understanding of emergencies and how to manage them" (Alexander, 2000). According to Alexander, the root causes of such a fragmentary nature of disciplines in disaster studies stems from the "fear of loss of identity and questions of power, since a strong sense of identity is the first necessity when marketing a research proposal. Moreover, interdisciplinary research is generally fuzzier in terms of its aims, progress and outcome than conventional discipline-based investigation (Alexander, 2000). Nevertheless, disciplines such as climatology, economics, geography, geology, law, planning, sociology, history, anthropology, literature and others are all today found to be more often than not in the studies and management of disaster risk reduction and form a multidisciplinary strand of professionals, the so-called "hazard community" (Mileti and Noji, 1999).

Besides these observations from the scientific disciplines themselves, the EU's framework program recognizes the need and challenge of interdisciplinary collaborations in general (European Union Research Advisory Board, 2004). The objective of improving opportunities for interdisciplinary endeavors has remained on the agenda of all seven EU framework programs and is now being transferred to the EU's subsequent research program Horizon 2020 (Allmendinger, 2015). A large body of literature is available that is tackling the challenges, benefits and risks of interdisciplinary research in general (Bridle et al., 2013) as well as demonstrating successful interdisciplinary research endeavors; e.g. with respect to coastal dynamics and human interventions (Marin et al., 2009; Prati et al., 2015; Pescaroli and Magni, 2015). This paper intends to add to this empirical evidence of 'what works' in interdisciplinary collaboration in disaster risk studies and what remains a challenge - and what are ways to approach the quest of better integrating scientific disciplines in disaster risk studies and elsewhere.

\subsection{Disaster risk reduction measures and society}

Europe's coastlines are a product of human cultivation leading to its ultimate settlement and resulted in engineering its characteristics to suit purposes of states, economy, and human recreation. Over the last century, the trust in technical intelligence and engineering capacities has led to bold new attitudes about building and living close to the sea, often interfering with the natural sediment transport of coastal systems and exacerbating erosion at many European coastlines. In addition, rapid coastal urbanization, mass tourism, maritime transportation and agricultural production have caused serious pollution problems and high demands on maritime resources. These problems are further accelerated by climate change, causing sea levels to rise and an increase in highimpact hydro-meteorological events. Coastal vulnerability is likely to increase due to two effects: 1) the increase of sea level rise and coastal flooding hazards; and 2) the increasing exposure to these hazards due to on-going coastal development (Martinez, 2017).

In 2004, research supported by the European Commission acknowledged that over $20 \%$ of the European coastline already faced serious problems, with thousands of kilometres affected by significant erosion (Eurosion, 2004). In 2007, the EU Parliament responded by issuing the European Floods Directive (European Commission), demanding member states to prepare flood risk management plans in accordance with their national laws and guidelines until a 2016 deadline. The directive is based on the principles of the safety chain: prevention protection-preparedness - and thus recommends a common strategy of risk management to all member states (Klijn et al., 2008; Ten Brinke et al., 2008).

Few studies so far acknowledge that sophisticated flood risk strategies do not automatically imply comprehensive, accepted and common approaches at the EU level and that this discrepancy may be the reason for the specific societal circumstances of the country or region for which the flood management plan has to be implemented or improved. Recent research undertaken by engineers (Nones, 2015) on the effectiveness of the implementation of the Floods Directive (FD) points out that the FD implementation still remains a large challenge from a technical point of view given "the very different and site-specific initial situations in each of the studied member states must be adjusted during the next implementation cycles, and eventually harmonised in compatible flood risk management plans" (Nones, 2015). Nones (2015) suggests that (1) "flood risk maps from different countries are generated according to the same methodology and with the same contents and that (2) flooding issues shall be considered by many different points of view ... considering the individual responsibility and preparedness of the citizens living and working in flood risk zones". Furthermore, research on flood risk management still excludes social, cultural, political and administrative realities in cases of flood events or risk management. This is primarily due to two reasons: (1) the focus was often placed on the technical solutions that would provide the desirable "safety"; and (2) in-depth interviews and observations are required for this kind of approach, often requiring different disciplines to collaborate e.g. sociologist, politic scientists with cultural anthropologist and environmental historians. For instance, by comparing two local responses to flood risk management plans, Martinez et al. (2014) analyzed the social and cultural barriers to and enabling factors for the implementation of DRR measures in two communities in the Baltic Sea. It was found that path dependencies and root causes of historical, cultural, political and economic relations amongst flood management institutions and people living in these communities played a significant role in shaping their particular approach towards flood risk management (Martinez et al., 2014).

One of the novel approaches of the RISC-KIT project was the joint collection and analysis of quantitative and qualitative data from scientists and engineers from various disciplines. These quantitative and qualitative data formed the basis of the RISC-KIT toolkit to reduce the risk of and increase the resilience to low-frequency, high-impact hydrometeorological events in coastal zones in Europe (Van Dongeren et al., 2017). The project was made up of ten case study sites in Europe, in which multidisciplinary research teams applied mixed data gathering methods while investigating in the "physical" and the "human" fields of the coastal environment across the social science and humanities (SSH hereafter) and natural science/engineering (NS hereafter) disciplines. In this paper, the authors analyze their experiences as a multidisciplinary research team in two case study sites in Italy and Portugal.

\section{Case study areas, methodology and findings}

\subsection{General approach used in the case studies}

In the proposal writing phase of the RISC-KIT project the stakeholder groups to be approached over the course of the project were discussed and agreed amongst project partners. Three main stakeholder groups were identified based on this process. Accordingly, interviews in the RISC-KIT project were carried out with: (1) decision makers (those with power in the case study area, e.g. coastal managers, land-use planners, 
civil protection authorities); (2) knowledge holders (those with expertise and some influence in the process, e.g. consultants and academics) and (3) informed citizens (active local groups, business owners, farmers, fishermen and residents living in the community) (see Table 1).

Researchers decided to work multi-methodologically and apply mixed research methods using qualitative and quantitative data and methods to understand risk perception, behaviour and response in the study areas (Brewer and Hunter, 1989; Bryam, 2012). For the conduction of individual interviews, a semi-standard interview protocol was developed by researchers of the social science and humanities followed by a discussion with the researchers from the natural science and engineering which lead to its final adjustment. Training on interview techniques, data recording and transcription of data was carried out by the researchers from the social science and humanities while the interviews were carried out by the researchers from the natural science and engineering. Interviews were guided by a protocol of written questions grouped into four categories: (1) culture and values; (2) perception of risk and sense of change; (3) perception of risk management; and (4) socio-ecological context.

The individual length of each interview varied between one and three hours. The questions encouraged lengthy, rather than short answers. Given that conversations mainly took place in a comfortable and relaxed environment (such as a meeting room in an office, an individual home or at a beach), it can be assumed that interviewees could entirely focus on the conversation. Accordingly, the informants were given scope to elaborate on their views and bring up topics they considered relevant.

Interviews were recorded, transcribed and handed over to the researcher from the SSH who analyzed the interviews and developed a set of first level codes (i.e. perceptions of risks, values, activities, measures, physical infrastructure, mode of governance) which allowed the categorization of the information from the narrative text. Text that fell into a specified category was copied under the appropriate code using qualitative software MAXQDA (see Fig. 2). Thereafter, text linked to these general codes was printed and placed separately in envelopes by each code. When the SSH researchers met, they noted and compared the names given to each pile of codes, and discussed about how they were similar or different, which led to further abstraction. Finally, the researchers contextualized and explained the coded text by literature research (including archival material) and discussed their findings with the NSH researcher. This resulted in the identification of DRR measures on a case study basis, based on the contextual information derived from the four categories (see Tables 2 and 3).

\subsection{Porto Garibaldi, Italy}

The Porto Garibaldi case study site is a $9 \mathrm{~km}$ stretch of coast located in the Ferrara and Ravenna provinces, in the region of Emilia-Romagna, northern Italy, facing the northern Adriatic Sea (see Fig. 1). It is located on the Po Plain to the south of the Po River Delta, the largest natural reserve in Emilia-Romagna and a UNESCO World Heritage site (González Dávila et al., 2014). The case study site and its hinterland are characterized by the presence of wide lagoons, wetlands and a network of canals. Most of the territory is low-lying, with elevations at the coast of between 0 and $2 \mathrm{~m}$ above sea level and large sections of the hinterland below mean sea level. The case study site can be divided into two sections according to its characteristics (urbanized or natural) and morphological and sedimentary behaviour. The urbanized part includes the coastal towns of Porto Garibaldi, Lido degli Estensi and Lido di Spina. The natural site is situated southwards of Lido di Spina, where the Bellocchio wetlands are located. There is a long cultural and historical tradition dating back to the Etruscan period that links the town of Comacchio and its surroundings with the lagoon. In modern times, human pressure on the coast - particularly after the 1970s - has exacerbated natural phenomena such as land subsidence, beach erosion and flooding during storms, endangering human settlements, economic activities and natural sites (Nordstrom et al., 2015; Villatoro et al., 2014). The sustainable
Table 1

Overview of interviewed stakeholder groups in both case study areas.

\begin{tabular}{|c|c|c|}
\hline Stakeholder groups & Description of knowledge & Rationale for interview \\
\hline SHI: Coastal manager & $\begin{array}{l}\text { High-knowledge of both } \\
\text { coastal processes and the } \\
\text { communities at risk. } \\
\text { Involved in coastal } \\
\text { protection and defence } \\
\text { against flooding and } \\
\text { erosion. }\end{array}$ & $\begin{array}{l}\text { To understand the risks } \\
\text { associated with the study } \\
\text { area in both physical and } \\
\text { social contexts. }\end{array}$ \\
\hline SH2: Land use planner & $\begin{array}{l}\text { High-knowledge of local } \\
\text { policies and policy } \\
\text { processes involved with } \\
\text { regulating coastal land use. }\end{array}$ & $\begin{array}{l}\text { To understand the local } \\
\text { polices, as well as processes } \\
\text { and stakeholders involved } \\
\text { in policy development. }\end{array}$ \\
\hline $\begin{array}{l}\text { SH3: Civil protection } \\
\text { agency/disaster } \\
\text { management agency }\end{array}$ & $\begin{array}{l}\text { High-knowledge of local } \\
\text { DRR plans including } \\
\text { technical and non-technical } \\
\text { measures for disaster risk } \\
\text { management. Planning and } \\
\text { preparation for safety of } \\
\text { citizens as well as property } \\
\text { during an extreme event. }\end{array}$ & $\begin{array}{l}\text { To understand local DRR } \\
\text { plans and non-technical } \\
\text { measures taken in the case } \\
\text { of an event. }\end{array}$ \\
\hline $\begin{array}{l}\text { SH4: Academic } \\
\text { working in coastal } \\
\text { zone }\end{array}$ & $\begin{array}{l}\text { Medium - high knowledge } \\
\text { of coastal processes, } \\
\text { policies and/or DRR } \\
\text { measures. Researching, } \\
\text { consulting, and/or working } \\
\text { with local planners and } \\
\text { managers. }\end{array}$ & $\begin{array}{l}\text { To obtain and understand } \\
\text { additional information in } \\
\text { regard to design and } \\
\text { implementation of the local } \\
\text { environment, policy } \\
\text { processes, and DRR } \\
\text { measures. }\end{array}$ \\
\hline $\begin{array}{l}\text { SH5: Consultant } \\
\text { previously engaged } \\
\text { in managing the } \\
\text { coastal environment }\end{array}$ & $\begin{array}{l}\text { Medium - high knowledge } \\
\text { of coastal processes, } \\
\text { policies and/or DRR } \\
\text { measures. Researching, } \\
\text { consulting, and/or working } \\
\text { with local planners and } \\
\text { managers. }\end{array}$ & $\begin{array}{l}\text { To obtain and understand } \\
\text { additional information in } \\
\text { regard to design and } \\
\text { implementation of the local } \\
\text { environment, policy } \\
\text { processes, and DRR } \\
\text { measures. }\end{array}$ \\
\hline $\begin{array}{l}\text { SH6: Local resident } \\
\text { previously affected } \\
\text { by the hazard }\end{array}$ & $\begin{array}{l}\text { Medium - high knowledge } \\
\text { of historical context of case } \\
\text { study site, understanding of } \\
\text { local environment, cultural } \\
\text { and social context. }\end{array}$ & $\begin{array}{l}\text { To understand the needs/ } \\
\text { perceptions/values of the } \\
\text { local population and to } \\
\text { learn about past events. } \\
\text { Will also provide } \\
\text { information on what is } \\
\text { politically feasible in terms } \\
\text { of the local community. }\end{array}$ \\
\hline $\begin{array}{l}\text { SH7: Chairperson of } \\
\text { local active citizen } \\
\text { groups }\end{array}$ & $\begin{array}{l}\text { Low - medium knowledge } \\
\text { of local environment, } \\
\text { political process and DRR } \\
\text { measures. May be involved } \\
\text { in consultation but little } \\
\text { further involvement. }\end{array}$ & $\begin{array}{l}\text { To understand the needs/ } \\
\text { perceptions/values of the } \\
\text { local population and to } \\
\text { learn about past events. } \\
\text { Will also provide } \\
\text { information on what is } \\
\text { politically feasible in terms } \\
\text { of the local community. }\end{array}$ \\
\hline $\begin{array}{l}\text { SH8 Local authority } \\
\text { (e.g. port, tourism } \\
\text { board, fishing, } \\
\text { housing) }\end{array}$ & $\begin{array}{l}\text { High-knowledge of coastal } \\
\text { activities (i.e. sectors) as } \\
\text { well as political processes } \\
\text { and the local communities. }\end{array}$ & $\begin{array}{l}\text { To understand the local } \\
\text { socioeconomic activities, } \\
\text { political processes and } \\
\text { sectoral policies. Will } \\
\text { provide data and } \\
\text { knowledge on socio- } \\
\text { cultural, socioeconomic } \\
\text { and socio-ecological } \\
\text { aspects of the study area. }\end{array}$ \\
\hline
\end{tabular}

management of the coast and robust risk management measures and plans therefore has a high priority for the authorities of the Emilia-Romagna region.

\subsubsection{Methodology}

Quantitative information gathered by the case study partners in Porto Garibaldi address physical parameters such as storm wave height, direction and period, water level, beach morphologies, topography of the coastal area and sediment characteristics in order to determine conditions, their changes and risks of the coastal zone. Due to long-lasting cooperation between scientists and authorities of the Emilia-Romagna region, a variety of risk reduction, preventive and mitigation measures have been adopted as standard procedure. The cooperation is mainly in 


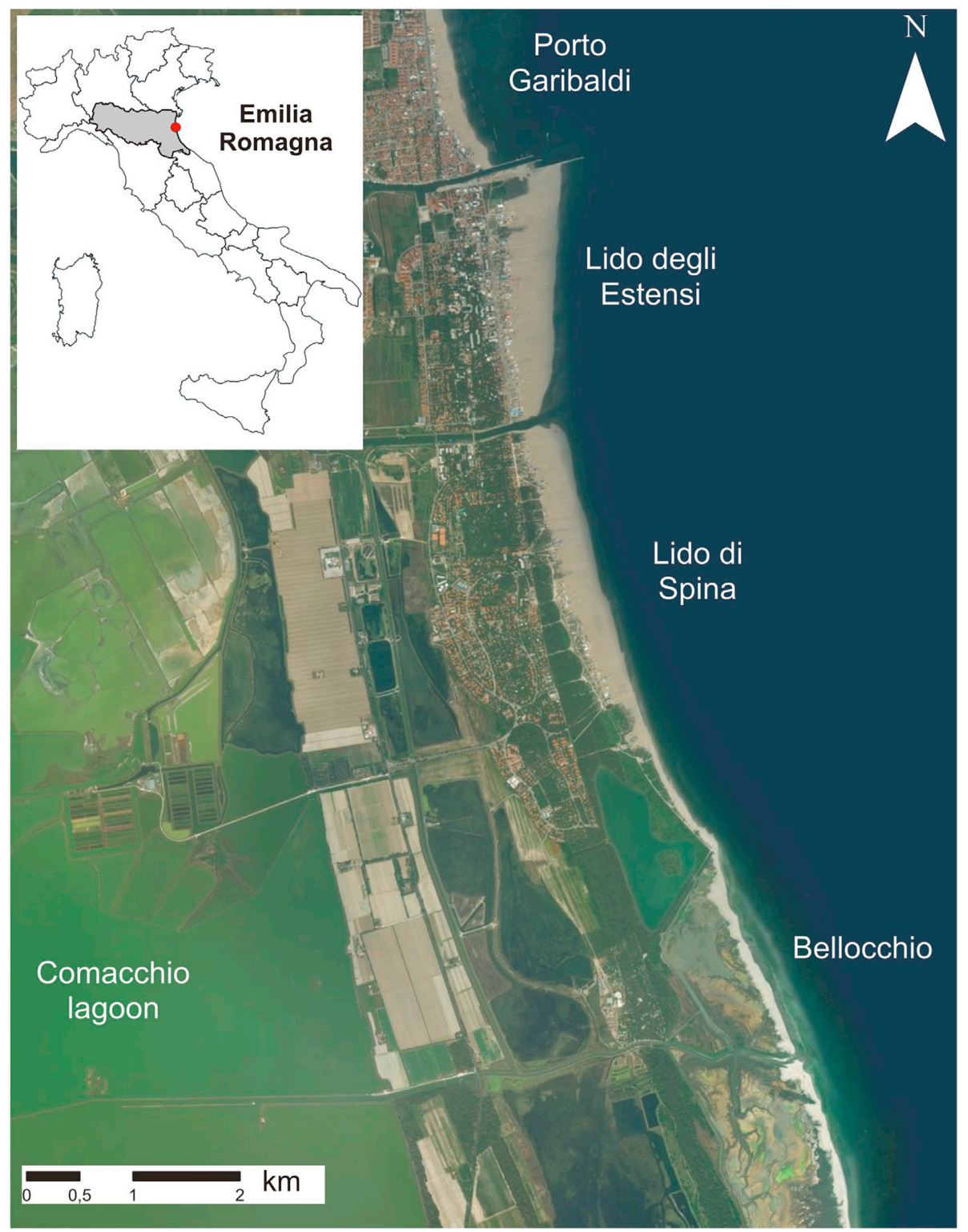

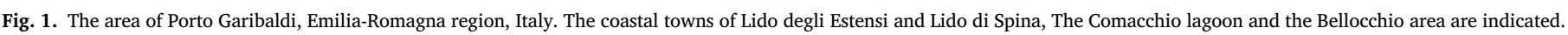

the form of the involvement of regional authorities (land use planners, coastal managers, decision makers) in European funded research projects, both as official partners (e.g. FP5 Coastview project (Albertazzi et al., 2003), FP7 Micore project (Harley et al., 2012, Ciavola et al., 2011), and end-users FP7 RISC-KIT project (Armaroli and Duo, 2017)). Three-day wave and water-level forecasts are undertaken by the Hydro-Meteor Climate Service of Emilia-Romagna (ARPA-HMC) on a daily basis, and weather warnings are issued to the Civil Protection Authority when specific thresholds are predicted to be exceeded. The thresholds have been defined through an historical analysis of past storm events that were observed to cause significant damage along the regional coastline (Armaroli et al., 2012). Furthermore, the regional authorities, in cooperation with the University of Ferrara and ARPA-HMC, have developed an operational Early Warning System that couples the forecasted forcing conditions with a numerical model of beach morphological change, in order to identify critical sites in several areas along the coast (Harley et al., 2016). The regional EWS was first implemented in the Micore project and then further improved after the project's completion (Harley et al., 2012). Therefore, it can be said that ongoing "physical investigations" by scientists in Porto Garibaldi coupled with the development of warning systems and alert mechanisms suggests that the Emilia-Romagna region appears to be well prepared for flood hazards, which the dynamics and consequences of also appear to be well understood.

The "physical investigations" described above were accompanied by a qualitative data collection as described in Section 2.1. Between 2014 and 2015, eight face-to-face interviews (guaranteeing anonymity to the interviewees) were carried out by the NS in Porto Garibaldi.

\subsubsection{Findings}

In the Emilia-Romagna region, regional policies and strategies for management of water, coastal zones, natural resources and land use are listed in the regional guidelines named Gestione Integrata delle Zone Costiere (Regione Emilia-Romagna, 2004), which were approved by the Regional Council in 2005, following European recommendations issued in 2000 and 2002 regarding Integrated Coastal Zone Management (V European Action Programme). The regional government issues the "Piano Territoriale Regionale" (PTR, Regional Territory Plan) that represents planning guidelines at the regional level. On the basis of the PTR, the provinces issue the "Piano Territoriale di Coordinamento 


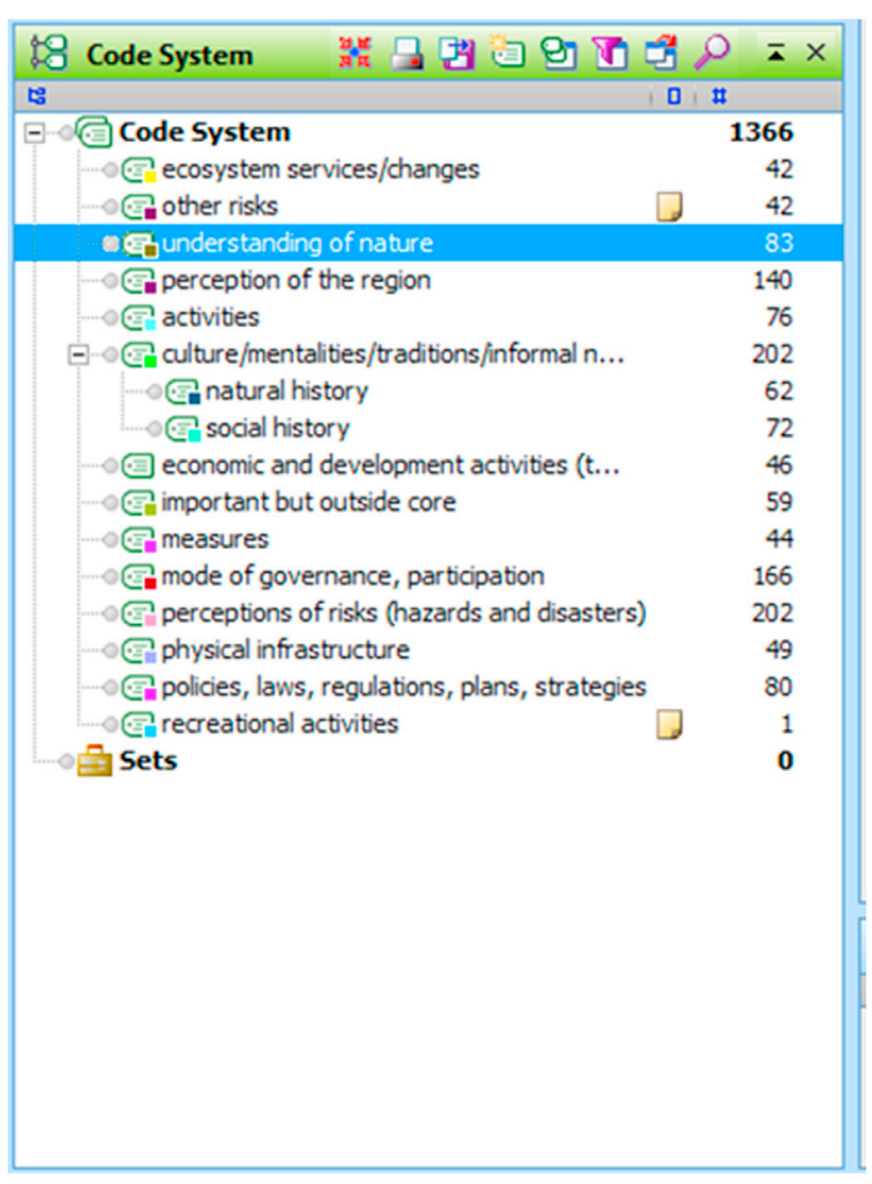

Fig. 2. Code system used to analyze narrative data.

Provinciale" (PTCP, Territorial Plan for Provincial Coordination). These plans are used to classify important elements of the territory (e.g. protected ecosystems, etc.) as well as for territorial planning guidelines at the municipality level.

Measures that currently take place in the area of Porto Garibaldi include the dredging of the canals to avoid deterioration of the water quality of the Comacchio lagoon as well as overflow of the canals. A further traditional method for DRR applied is an ad hoc measure called "winter dune" construction that has demonstrated to be, in some cases, useful to avoid marine ingression (Harley and Ciavola, 2013). In 2006 the practice was regulated by guidelines that will soon be translated into compulsory regulations, in order to avoid erosion problems usually related to inappropriate construction of these artificial mounds.

Table 2 shows a list of DRR measures that were stated by interviewees. This table gave researchers a first overview of relevant activities from the perspective of the interviewees in Porto Garibaldi that were subsequently discussed with the team of scientists working in the case study area and contextualized through the background information from interviews and literature research.

In addition to the interview process, in autumn 2015, a multidisciplinary team of researchers carried out a local roundtable discussion with key stakeholders from the Emilia-Romagna coastline at the regional premises in Bologna. The decision to hold the discussion was taken by the researchers from the natural science and engineering after a major storm event had affected the region in the winter of 2015. It was hoped to gather further expressions on disaster measures with a relatively fresh memory of the event. Much to the surprise of the research team, an unforeseen discussion arose amongst staff from the mid- and top-level civil protection agencies concerning an alert activity during the storm event of
Table 2

Existing and proposed DRR measures for Porto Garibaldi.

\begin{tabular}{|c|c|c|}
\hline Risk & Measure & Interview \\
\hline Flood & $\begin{array}{l}\text { "The focus should be on identifying new ways of thinking about } \\
\text { citizen safety and self-management, in short, to be implemented } \\
\text { also by citizens themselves, not only by public authorities in } \\
\text { charge of land safety." } \\
\text { Preparedness } \\
\text { Early warning systems } \\
\text { Emergency management/response } \\
\text { Actions to discourage risk-taking behaviour (e.g. building } \\
\text { and safety rules taking into account the local hazards) } \\
\text { Restoration of coastal dunes or pseudo natural levees } \\
\text { "Operating on several fronts" (e.g. combining multiple } \\
\text { measures and using alternatives) } \\
\text { Submerged barriers } \\
\text { Artificial dunes } \\
\text { "Empty spaces. This should be managed with intelligence both } \\
\text { along the coast and inland, keeping them empty." } \\
\text { Winter dune construction (a local practise whereby at the } \\
\text { beginning of each winter sand is scraped from the lower to } \\
\text { the upper beach building a temporary flood protection, } \\
\text { and pushed back at the beginning of summer) } \\
\text { Guidelines on self-protection measures (e.g. winter dune } \\
\text { construction) so that impacts are not worsened } \\
\text { Coastal regeneration } \\
\text { Ecological compensation to urbanized areas } \\
\text { Moving inland and retreating from the coastline } \\
\text { Creating wetlands } \\
\text { Building houses on piles } \\
\text { Teaching beach establishment owners to build and be } \\
\text { prepared for flooding (e.g. putting electrical wiring in the } \\
\text { ceiling instead of burying them underground) }\end{array}$ & $\begin{array}{l}\text { Interview } \\
4, \mathrm{SH} 8\end{array}$ \\
\hline Erosion & $\begin{array}{l}\text { Beach nourishment } \\
\text { Re-naturalising dunes }\end{array}$ & $\begin{array}{l}\text { Interview } \\
3 \text {, SH } 8\end{array}$ \\
\hline
\end{tabular}

5 February 2015 (named "St. Agatha storm"; Trembanis et al., 2017). It turned out that the roundtable discussion brought to the surface communication problems that had been overlooked during the major event of 5 February 2015 (Ciavola P. personal communication). The discussion further deepened the impression raised by interviewees during the interview process in Porto Garibaldi regarding blurred communication amongst authorities responsible for coastal management at all levels, as well as involvement of the general public in knowing, and therefore accepting, the procedures of early warning systems and actions activated to protect the coast: "A completely shared process should be implemented, involving everyone, starting from public authorities, down to individual citizens, since everyone has some level of responsibility. It is therefore essential that these choices are shared, otherwise it would be unthinkable that public authorities could take action everywhere. (...) There should probably be a greater involvement of technical experts, so that they can in turn serve as interface with the political level." (Interview 1, SH 2)

In the Porto Garibaldi case study, activities regarding DRR measures are not well-integrated and local actors and institutions do not take shared actions. Decisions are instead made most of the time at different levels following different methodologies, without an integrated strategy (Barquet and Cumiskey, 2017; Basco-Carrera et al., 2017). Dissemination and exchange of activities to the general public and among institutions are formally structured but these activities are not translated into shared practices.

Consequently, the interviews contributed to a list highlighting these concerns raised by stakeholders (see Table 2). On the basis of what is feasible and already implemented at the regional level, researchers made the decision to focus on the development of winter dune construction coupled with measures to reduce the vulnerability of receptors for Porto Garibaldi.

\subsection{Ria Formosa, Portugal}

The Ria Formosa coastal lagoon is situated at the southernmost end of 


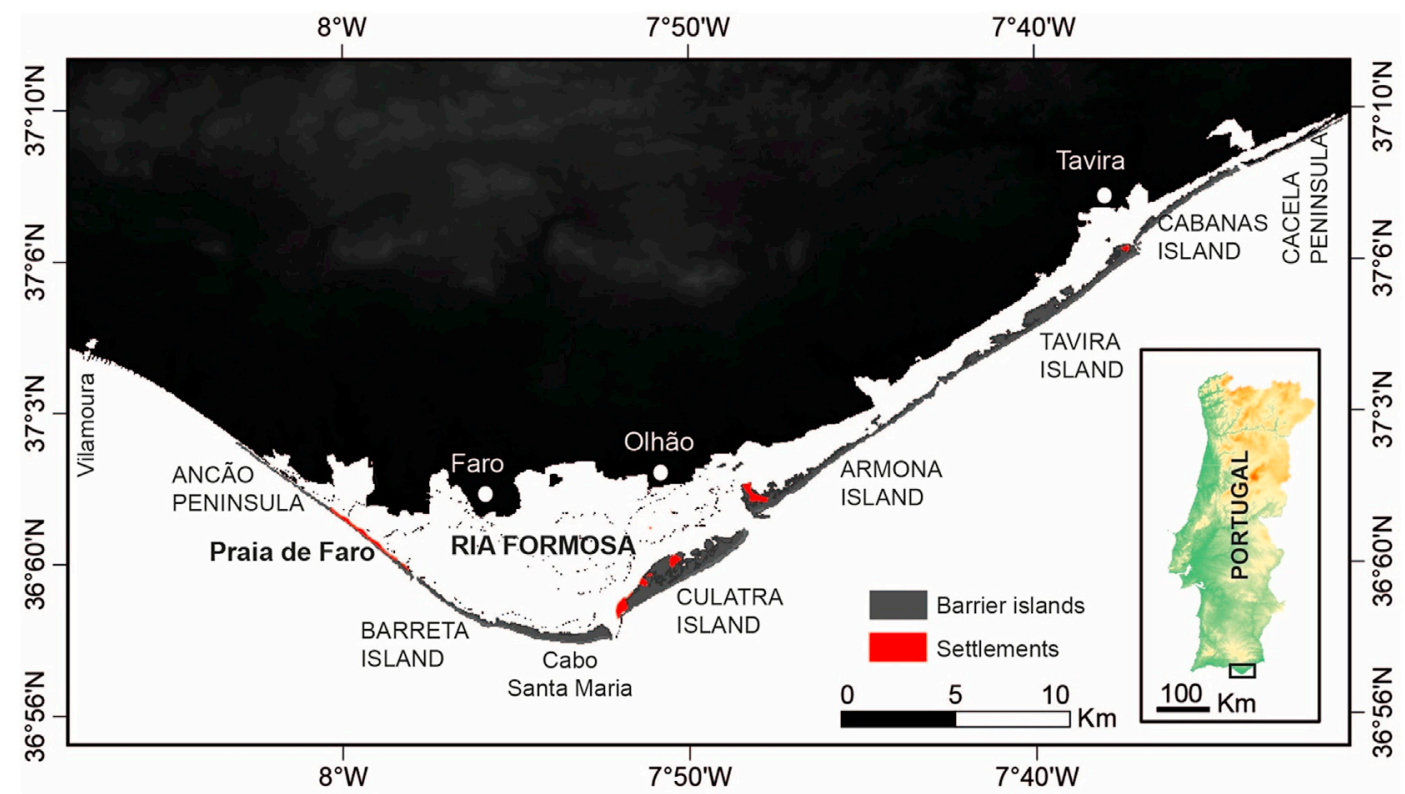

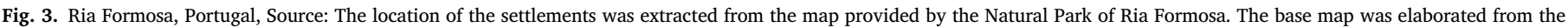
$30 \mathrm{~m}$ resolution digital terrain model available at ESRI Portugal.

the Portuguese coast. It consists of a lagoon protected from the direct action of the open sea by five barrier islands and two peninsulas separated by six tidal inlets, and spatially distributed to produce a cuspate shoreline that extends over $55 \mathrm{~km}$. The geographical, geomorphological and climatic conditions of the Ria Formosa make the lagoon a breeding and transit area for fishes and birds. As a result, the area is internationally recognized and protected within the Wetlands of International Importance (Ramsar) Convention and the Birds and Habitats Directive (Natura 2000 Network). At a national level, the Ria Formosa is integrated within the Natural Park network of Portugal since 1987 (see Fig. 3).

Storms impact the area every year and wave heights above the defined storm threshold of $3 \mathrm{~m}$ are relatively frequent, constituting the major source of threats to the area as they may result in substantial beach erosion and overwash. A major storm occurred in 1941 (Freitas and Dias, 2013) followed by other important events during the 1960s (Almeida et al., 2011), with crucial consequences for the tuna fishing facilities owned by the fishermen communities in the barrier islands (Garnier et al., 2017). During the end of the 1970s, there were also severe storms that affected the human population. During autumn 1989 and winter $1989 / 1990$, new storms hit the barrier islands with significant consequences not only for the natural sand barriers but also for the artificial infrastructure and houses (Freitas and Dias, 2013). Severe overwash and shoreline retreat together with the partial destruction of seawalls and houses resulted in the erection of emergency rock constructions on the beach. During the winter of $1989 / 1990$, a seawall was built and afterwards partially destroyed ( $230 \mathrm{~m}$ of the seawall collapsed). The damaged areas (road, walls and buildings), were rebuilt in exactly the same spots. Additional intense storms in the winters between 1996 and 2010 resulted in further damage of houses and overwash reaching the lagoon (Almeida et al., 2012).

Praia de Faro is located in one of the two peninsulas situated in the Ria Formosa coastal lagoon. Like all islands and peninsulas in the lagoon it is affected by coastal erosion from storms. Most of the buildings in the central part of the study area are second residences and buildings related to tourism (camping, hotels) and restaurants. Even though the islands and peninsulas are included within the Marine Public Domain, some parts, as it is the case of the central part of Praia de Faro, have been claimed by the local municipalities due to the interest generated by the tourist activities. In the case of Praia de Faro, the population has access to public tap water and power network and pay taxes even if their buildings are illegal. The fact that many of the buildings have direct access to the ocean shoreline by crossing the dune, consequently reduces vegetation cover, increases sand loss and contributes to dune destruction (Feagin et al. 2015).

Following the series of destructive events outlined above and with the main aim of protecting human lives and the environment, the central government in Lisbon (who is responsible for defining the general guidelines for the coastal zone management plan) decided that the houses built in the Natural Park should be removed. This resulted in the development of a new management plan for the natural park in 2005. The implementation of the plan extended over several years due to several constraints, with the public reaction against the removal of houses being the most significant factor. In fact, house removal only partially commenced in 2015 and included only secondary residence houses within the settlements managed by the Regional Portuguese Agency of Environment (APA). These actions provoked intense discussions amongst civilians, including some riots.

Occupation at Ria Formosa only dates back to the mid 19thth century when fishermen started to scatter across the various islands of the lagoon (Portuguese Environment Agency, 2017). The cultural values at Ria Formosa are closely linked with traditional lifestyle of fishing and the recreational usage of the beautiful natural environment. Unlike in Porto Garibaldi, background research and interviews indicated that in Portugal there is not a general notion of DRR measures. In fact, the Portuguese language does not hold a name such as "plano de redução de desastre" and so DRR measures often are a part of coastal management plans or integrated among those (Ferreira O. personal communication). However, at a local level there are management plans devoted to reducing risk as it is the case in Ria Formosa, where these measures have a twofold objective; on one hand they are planned to ensure environmental conservation, and on the other hand, they also serve to reduce risk.

The contradictions imposed by unclear definitions of disaster risk management coupled with blurred roles of its implementation are best exemplified in the current contradictions of the risk management at Praia de Faro, a narrow dune strip between the Atlantic and the Ria Formosa lagoon. The actual division of the community includes three sectors: the central part, which is more densely built and managed by the council, and the western and eastern parts, occupied by fishermen communities and managed by the Natural Park and the Environmental Portuguese Agency (Costas et al., 2015). 


\subsubsection{Methodology}

Similar to Porto Garibaldi, in Ria Formosa natural scientists investigated the physical parameters of the beach based on hydrodynamic conditions associated with historical storm impacts, extreme wave runup and long-term morphology. Naturally, and similar to Porto Garibaldi, interview experiences amongst the natural scientists were rather limited and in addition to semi-structured open ended interviews also multi-choice questionnaires were applied. In 2014, 12 interviews were carried out with an average duration of about $1 \mathrm{~h}$.

Training, execution of interviews and transcription of narrative data followed the standard procedure described in Section 2.2.1.

\subsubsection{Findings}

Table 3 shows a list of DRR measures that were stated by the interviewees. Again, measures were subsequently discussed with the team of scientists working in the case study area and contextualized through the background information from interviews and literature research.

Throughout the consultation process, numerous remarks were made on the usefulness of such activities, often based on long-time daily observations by local fishermen and community members in general, which proved that local residents understand the natural dynamics of beach erosion and aeolian sediment transport very well and led to suggestions as to a variety of measures. For example, voluntary services such as planting dune vegetation were offered during the interviews: "I would like very much to participate on improving the state of the island. I would like to help planting herbs and would like very much to take care of them ... They (the local authorities) should do something with the plants of the dune ... if they ask people to volunteer, they will help and it will be very cheap." (Interview 3, SH6). In fact, a coastal manager revealed the view "that we have not invested in protection of the system from the impact (of frequent storms) ... I think we are not ready for what is coming ... for example since 2002 there has not been any activity on implementing new fences (around the dunes to recover), so this is a lot of time without doing anything." (Interview 8, SH 1). Community members believe they are prepared to take care of themselves in an emergency event. However, interviewed local residents equally expressed their concern of not having knowledge about early warning- or evacuation procedures for the Ria Formosa. "I think they should have an evacuation plan ... but we never have been contacted for a training plan ... and we are in the XXI century ... so ... I would say that we are abandoned, but at least we are healthy." (Interview 3, SH6)

From the perspective of an informant from the civil protection agency: “... the people living there (at the Ria Formosa) are extraordinary. They have a fantastic resilience because the people live there always ... they have a historic knowledge and they always know if something is going to happen. However, the tourist ... the people who do not live there, are actually a problem, because they do not know how to react, however the people living there, even help us to deal with the problematic situation, they are very

Table 3

Existing and proposed DRR-measures for Ria Formosa.

\begin{tabular}{|c|c|c|}
\hline Risk & Measure & Interview \\
\hline \multirow[t]{6}{*}{ Erosion } & Reinforcement/recuperation of dunes & SH 6, SH 1, \\
\hline & Beach nourishment & SH 41 \\
\hline & Demolition of beach houses & Sh 6 , SH 4 \\
\hline & Replacement of stones/artificial reefs & SH 1 , SH 4 \\
\hline & Prohibition of dredging sand for commercial purposes & SH 6, SH 3 \\
\hline & $\begin{array}{l}\text { Channel dredging and sand replenishment in the beach } \\
\text { within the vicinity of the dredged channel }\end{array}$ & SH 6, SH 4 \\
\hline \multirow[t]{8}{*}{ Overwash } & Evacuation of people from the islands & SH 3 , SH 4 \\
\hline & $\begin{array}{l}\text { Warning if waves are higher than } 3 \mathrm{~m} \text { (although for } \\
\text { ships) }\end{array}$ & SH 4, SH 6, \\
\hline & Evacuation plan training & SH 1, SH 6 \\
\hline & The natural park Ria Formosa - as a means to preserve & SH 6 \\
\hline & ecosystems and strengthen natural resilience & SH 6 \\
\hline & Environmental education & SH 6 \\
\hline & Public discussion sessions & \\
\hline & Type of construction and used materials & \\
\hline
\end{tabular}

resilient." (Interview 5, SH 1) Hence, it can be hypothesized that the trust of local authorities in the intuitive capability of the local residents to cope or escape in time in case of disasters is rather high and this might help explain the relaxed attitude expressed by an informant from the civil protection agency regarding the implementation of emergency plans for Ria Formosa: "The plan, from my personal point of view, is just an instrument because in practise the things happen in a different way....I have to believe that all the people will do their best, we are confident that this will happen with our partners. However, we are not so confident with the population because they are the ones at risk, and losing their belongings, they get nervous and not so easily controlled." (Interview 5, SH 1) This expression confirms a mutual low level of trust between the civil protection agency and the local residents of Ria Formosa as they were equally and often contested in the interviews with local residents, e.g. "They (the local authorities) have never met with us, they only invited us when everything is decided, they never came to ask us, like you (the interviewer) are doing." (Interview 4, SH 6).

Views on the state of the art of the DRR planning are further enriched from the perspective of an informant from the stakeholder group 'scientist': "As far as I know there is not a protocol for early warning .... what happens is that the local civil protection agencies, if there is a storm coming and it is likely to impact the coast, will move and go to the field to check and have an eye on the situation. They may eventually close the road and regulate the transit to the peninsula through the bridge in order to avoid people from Faro to go to there to see the overwash and the storm, but not necessarily take the people from the island. They usually act by feelings". (Interview 9, SH 4). The interviewee further explained a personal conviction that there seems to be "no public notion on how much it costs to have a beach or to implement a $D R R$ and therefore people in general do not understand easily why it is not done. Most of the people living on the coast don't really care for environmental protection, what they ask for is to build large structures to protect them and their houses and don't easily understand the consequences of sea level rise or coastal erosion - they want that to be stopped with hard structures and after that we will see if there is beach and birds left ..." (Interview 9, SH 4).

Portugal still keeps a relatively powerful central government, although the procedure of decentralisation has already begun. Decision making about and implementation of DRR measures seem to happen relatively ' $a d$ hoc' and often at the local level, involving different stakeholders with different degrees of power and somewhat contrary agendas. "It is not a question of money, it is a question of political courage, it is mostly that, the only way that could change, between the local and the national power, would be if a very strong storm impacts the area, and then that is it ..." (Interview 6, SH 1). Although various DRR measures are tested in Ria Formosa, they do not seem to be built around a clear mandate or strategy. In the course of the interview process it became evident that the most fundamental problem seems to lie in the lack of communication and trust between civil protection agencies and coastal managers on the one hand, and local residents on the other. While local residents claim that they were not provided with adequate information on emergency/evacuation planning and options/compensation for housing outside the vulnerable dune environment, authorities view local residents as troublemakers rather than as partners for building resilience in Ria Formosa.

Based on the above information and their own assessment, case study partners from Ria Formosa chose to bring DRR measures forward, which focus on broader exchange of information on coastal risk management and initiated a roundtable discussion with local decision makers from councils, coastal managers, and researchers. Even though local residents were also invited to the discussion, they did not join the discussion, likely due to the bad relationship between this group and institutions derived from the radically different points of view in terms of DRR measures. Furthermore, the researchers felt that "unfortunately, we have not been able to represent how acceptance of a measure can actually reduce the risk at several levels (as this could not be found in the literature), so that we finally included education as a non-physical measure, although the original idea was based on the results from the interviews that pointed out the need for building and feeding and transforming into actually active and bi-directional communication channels for trust building." 


\subsection{Methodologies used in the case studies and findings}

In both case study sites identical approaches were used for conducting and analysing interviews. A small difference occurred in the case of Porto Garibaldi where an additional workshop with further stakeholders took place shortly after a main storm event had occurred in February 2015 (see Section 2.2.1). Based on these stakeholder consultations and the knowledge of the case study owners regarding the specific bio-physical and societal constellations in their case study site, the best suited DRR measures were chosen. Regardless of the differences of the chosen DRR measures (winter dunes in Porto Garibaldi and better information on vulnerability and education on DRR measures in Praia de Faro) it seems that better communication and collaboration amongst stakeholders remain a core issue in both case studies.

\section{Experiences in interdisciplinary collaboration}

In this section, we draw on the individual experiences of five researchers, three of whom have been trained in the natural sciences/engineering and two in the social science and humanities. The collaboration, which originally started from each researcher's perspective, gradually became a multidisciplinary exchange while trying to identify and bringing forward locally acceptable DRR measures in a certain case study context. Our experiences are grouped into three categories: (1) Perception of collecting qualitative data; (2) Challenges of processing qualitative data; and (3) Potentials for interdisciplinary collaboration. Each category is illustrated by statements of the researcher from the respective disciplines that are grouped in the two broad overarching disciplines Natural Science/Engineering and Social Science and Humanities.

\subsection{Perception of collecting qualitative data}

\subsection{1. $S S H$}

"There is a mistaken assumption among non-social scientists that qualitative data is "soft" data, what is collected when you cannot collect quantitative "hard" data. In actuality, qualitative data is distinct from quantitative data, and is collected to help us understand knowledge, values and behaviours that cannot be understood, in a valid and reliable manner, with quantitative data. There are sociocultural phenomena that cannot be measured by interval level scales. Often these phenomena are some of the most important human emotions and behaviours. Collecting qualitative data is one of the most useful mechanisms for illustrating the difference between qualitative and quantitative. The experience of developing an interview instrument, allowing interviewees to respond to questions in an open manner, and the interviewer listening and probing in a nonjudgmental manner provides powerful insights on how humans develop knowledge and values and apply them to situations affecting their lives, all the time drawing upon experience and expertise."

"Through the questions of the colleagues from the natural sciences I reflected why I would pose a particular question and what the answer to this question would mean for my methodological frame. I also understood that - from my point of view - some questions could be rather complicated or not meaningful for someone from the natural disciplines. This was for instance the case with a question where interviewees were asked to explain their view of nature by referring to one of four sketches accompanied by a description which classified nature as either benign, ephemeral, tolerant or capricious. For me as a researcher of the social science and humanities answers would allow to make a general assessment of the risk perception of the interviewee but of course that needed to be explained and discussed with the researcher from the NS."
3.1.2. NS

"Although I have spent many years collecting physical data on the coast, this was the first time that I had ever collected qualitative data. For me, the process of undertaking lengthy interviews with a range of different stakeholders was a real eye-opener as I was able to hear firsthand the disparate perceptions of coastal risk among them, even when they came from the same region. It really highlighted to me the complexities in developing DRR strategies and that the cultural values of the community really help determine the pathways one should take to developing such strategies. I found that it was a lot more effective to let the stakeholders speak expansively on each topic as often their opinions and values were quite nuanced and hidden within specific words that would not have been able to be ascertained had they simply responded to direct questions"

"Interviews represent a new experience for us, because we usually deal with physical data gathered both directly in the field or taken from instruments and then analysed. The main difference is that dealing with persons and their thoughts discloses a large number of issues that we usually do not consider. Our work and data gathering are focused, obviously, on the physical system in order to better understand complex dynamics, but we should also care on how to present our findings to whom is in charge of making actions that can prevent damages and disasters. Communication between researchers and managers should become more effective, in order to let them properly use our findings, to activate actions that can be really useful for the society."

"My previous experience running interviews was very limited, as I had done that only once before and it was a multi-choice questionnaire ... However, the interviews within RISC-KIT were completely different as the responses are open-ended, depending to a great extent on the type of person you are interviewing and how confident they feel talking with us. In this regard, I felt that it was very important first to build a relaxed environment. This would always ensure that the interviews were productive as the people felt confident and relaxed, as if they were talking with someone really interested on their opinion, and who would respect whatever opinion they have about anything."

"Letting them free to talk was, however, the best way to disclose their real thoughts that came out at the end of their answer and that were sometimes different, or even in contradiction, with what they said at the beginning."

\subsection{Challenges of processing qualitative data}

\subsection{1. $S S H$}

"The challenges to collecting valid and relevant qualitative data include 1) identifying who are the key informants, and making sure you have a representative sample that includes diverse viewpoints from different stakeholder groups; 2) developing questions that promote interviewee discussion and reflection, 3) recording and analyzing the collected data, which today is assisted by computer text software, and 4) writing up and presenting the results in ways that decision makers and other researchers find valid, convincing and useful".

"Qualitative data of course differ from quantitative data. The most noticeably difference perhaps is the fact that qualitative data often give room for interpretation whereas qualitative data e.g. a water level is a certain figure. However, when analysing qualitative and quantitative data it was recognized that such certain figures can be also subject to interpretation and perception. For example, a water 
level arriving at a undefended beach strip several centuries ago perhaps killing many people would be judged to be 'higher' or more dangerous than one of the same magnitude which arrives at a coast with a defence structure well adjusted to this magnitude. Through comparisons like this it became evident that (1) qualitative and quantitative data seem to be more related to each other than thought and (2) hence that they can work "hand-in-hand' by complementing each other and helping to define the best possible DRR measure.

"It is also particularly relevant to mention that some of the qualitative data obtained from the interviews were integrated into the models used by the NS scientists."

\subsubsection{NS}

"I found that the biggest challenge was identifying the right set of people to talk to. Obviously you would like to select people that represent the wide spectrum of values for that community, but I wondered if my own values were guiding that choice. When conducting the interviews, because they were free-form and I had never conducted interviews before, I was not sure when I had exactly enough data that would be useful for the social scientists. Often the interviewees strayed "off-topic" and I tried to guide them back onto more relevant discussion, but I wasn't sure how to best do this. I also found that stakeholders representing government organisations tended to speak in an official manner and it was difficult to break the veneer and uncover their own personal beliefs"

"I learned that the perception that researchers like me have on coastal issues are mostly correct, but that each component of the chain that goes from the regional/local government down to local people is made of contradictions and communication barriers that are difficult to overcome".

“... the limited or not correct memory of past actions carried out by regional authorities to mitigate the effect of extreme events, with only few exceptions (coastal manager, land use planner), and the focus on recent and contingent problems, saying that what had been done to limit the negative effect of beach erosion and flooding is not effective, which is only partially true".

“... I must say that in most of the cases the interviewed stakeholders were quite well-known by the case study owner (CSO) making easier the contact. Yet, in some cases, the fact that I was running the interviews, and they did not know me (I was anonymous for them), made things easier in some cases. For instance, the interview to the fisherman representative started quite wrong as the CSO was there, and he was introducing the process and for that man the CSO represented an institution, and he was against any. However, after all the interview went very well as he relaxed through the interview".

"Land use planners and coastal managers are very well aware of the main issues of the case study site and wanted to underline their personal point of view. They talked frankly of the importance of natural ecosystems that are present at the site, but their actions as coastal managers are in contradiction with what they said. They admitted that natural systems are very important and unique environments along the coast, but most of their institutional actions have to face the reality, which means that they have to take into account the economic sector that is related to tourist activities that are, in a sense, not in harmony with ecosystems. They wanted to stress the beauty of the site in terms of natural landscape, but on the other hand they said that "birds neither vote nor pay taxes".

"Different answers were provided by local people (fishermen and owners of concessions ....). The fishermen were more concerned about local traditions and on the importance of protecting the site from flooding; the owners of concessions complained about the role of regional and local authorities as not enough actions were implemented to protect their activities from their point of view. The natural park manager stressed only the ecological, biological and natural importance of the park, complaining that money was spent to protect concessions but not natural ecosystems; the (former) Head of the Park showed her vision of an ideal coastal system where it would be possible to conciliate economic activities and natural systems, if only the institutions had enough courage to go against some of the requests of concessionaires, thinking more in a long-term perspective and encourage a re-naturalisation of the coastal area".

\subsection{Potentials for interdisciplinary collaboration}

\subsection{1. $\mathrm{SSH}$}

"The collection and processing of qualitative data by natural scientists have the potential to build bridges between the natural and social sciences. The experience of interviewing and listening to respondents allows the researcher to suspend his or her cultural biases, at least temporarily, and engage in the intellectual task of trying to understand another cultural viewpoint. In many ways, this is a research problem, fundamentally not that different then studying a biological or physical problem. The subject matter may be different, but the attempt to objectively understand a socio-cultural system uses scientific reasoning and practice. The main difference is that that subject matter are systems of knowledge, values and behaviours, rather than ecosystems and biological processes, both of which have patterns for the scientists to elicit and interpret."

"Different cultural groups think and feel differently about their experiences with coastal hazards and hence act differently in their preparations. Applying a socio-cultural research framework will help to unlock opportunities for success in building ownership towards coastal risk management amongst coastal stakeholders in Europe.”

\subsubsection{NS}

"My experience in working in a multi-disciplinary project like RISCKIT has definitely given me an increased awareness of the complexities in social and cultural values of a region and how they could be taken into account in my work as a coastal engineer. Having now seen how social scientists apply qualitative data I now have a much greater understanding of its use and am encouraged by how both quantitative and qualitative data can be used hand in hand. I have also learnt some skills on how to interview effectively which I hope to apply again"

"What I have learnt from the interviews is understanding the reason why people decides to live in the coast, regardless of the risk, and in this regard, to understand how and whether they perceive the risk and how they adapt, or not, to it."

"I discovered that my thoughts on the interview and what I remembered as main outcomes were not fully on the lines of what was really said. Re-listening, transcribing and translating were very useful to list their real thoughts and not their thoughts filtered by my perception".

"Through the guided trips and participation in some interviews in the case study areas my practical knowledge of the physical manifestation of flood risk measures (i.e. how beach scraping is well done and why it can be done wrong) sharpened. These are great assets for further investigations".

"Through the whole process I learned that there are two kinds of residents, the ones attached to the beach, and who do not care about the money, but about their life quality, and the ones that pretend to be 
attached to the beach, but do not know about risk, and do care about compensations. After this process, my point of view changed ... The process of the interviews helped me to actually understand why people decide to live with risk".

“... from what I am getting from the interviews the major limitation on accepting the DRR measures is the lack of participation by the residents or fishermen, or even the lack of explanation of the measures, I saw that they need to explain their situation, and more importantly, to understand the reason behind the decisions of the local or national governments because in most of the cases they have the result of a decision without any sort of explanation ... somehow the situation you got from the conversation you recorded and sent."

"The way they perceive the risk is somehow the result of learning from the sea, it seems that they have a fluent communication with the sea, but not with the authorities."

\section{Discussion}

The scientific debate on interdisciplinary collaboration in disaster risk reduction has steadily developed, leading to the conclusion that human resilience to natural disasters cannot be achieved while disciplines are working in isolation. Disasters risk studies and management have to address hazards from the perspectives of the natural, physical and social science and humanities, the behavioural and engineering sciences. Teams of hundred of experts from academia and practitioners found "that hazard losses, and the fact that there seems to be an inability to reduce such losses, are the consequences of narrow and short-sighted development patterns, cultural premises, and attitudes toward the natural environment, science, and technology (Mileti and Noji, 1999).

As illustrated in Section 3 of this paper, collaboration amongst profoundly different disciplines such as physical science, engineering, cultural anthropology and environmental history, are possible and moreover can be productive for both the professionals undertaking them and for their studies. The qualitative data which were obtained on personal values, perception of risk and its management together with contextual information about the socio-cultural shaped ecological environment lead to the selection of DRR measures in the case study sites. Qualitative data also allowed the NS researcher to understand contradictions in human risk management and behaviour whereas quantitative data alone would not have supported such insights. In this respect, the information obtained helped the different disciplines to work "handin-hand'.

In addition the interdisciplinary collaboration created some unexpected insights, such as that "characteristics of risk perception seem to be shaped by place attachment, underestimation of impact probability and lessons learnt, and inherent cultural aspects" being subsequently made the focus of an interdisciplinary article (Alexander, 2000). Nevertheless, it seems that certain requirements are beneficial if not profoundly important for successful interdisciplinary research such as good grounding in one's own discipline and familiarity towards neighbouring disciplines. Regardless of those, the most important prerequisite however seems to be a true personal interest of the professionals to broaden their own disciplinary or practical horizon coupled with curiosity, openness and respect for neighbouring disciplines and more distant ones. In our case, the NS researchers provided significant time for working together and in person with the SSH professionals and vice versa. Various stays including field trips and informal meetings with stakeholders, open-ended agenda's as well as curiosity and openness to apply other methods out of their comfort zone helped creating an atmosphere where they felt that they can "afford" to engage with the "unknown" of another discipline, here environmental history and cultural anthropology. Finally, coordinators who are open to interdisciplinary methods and approaches do help, facilitating multi- and interdisciplinary collaborations like the one which has been subject of this paper.
In the well-established structures of EU research, projects are usually organized around rigorously separated work packages and deliverables with project coordinators stemming from a single scientific discipline, either the natural or the social science and humanities. Furthermore, the lack of a pilot phase to develop a shared interdisciplinary research agenda often makes it difficult to share synergies amongst disciplines. Accordingly, European projects do not seem to be the easiest vehicles for deep interdisciplinary collaboration. Instead, collaboration often becomes a transaction where one discipline works on one aspect of a project and a different discipline on another. Although these structures can be effective in terms of collaboration, the accumulation - rather than the integration - of knowledge appears the more likely outcome.

Collaboration amongst disciplines can also be for the sake of form only, inviting a discipline into a project (often the social science and humanities) when most of the work has already been done, or assuming that these disciplines will give the research the glimpse of societal testimonial. In these cases the social science and humanities serve figuratively as the "fig leaf". Different schools of thought, for instance within the social sciences, can however also hamper collaboration in disaster studies (Alexander, 2000). As described at the beginning of this paper there are historical roots for the divergent development of scientific disciplines as well as the lack of respect that the disciplines have developed for one other. The experience of an interdisciplinary project such as RISC-KIT suggests that these barriers can be greatly reduced when all disciplines work together in all phases of a project, including the collection of qualitative and quantitative data.

\section{Conclusions}

"Between 1998 and 2009, Europe suffered over 213 major damaging floods, including the catastrophic floods along the Danube and Elbe rivers in summer 2002. Severe floods in 2005 further reinforced the need for concerted action. Between 1998 and 2009, floods in Europe have caused some 1126 deaths, the displacement of about half a million people and at least $€ 52$ billion in insured economic losses" (European Commission, 2017). Recent disasters such as the 2010 Xynthia storm in France, the 2013 Xavier/St. Nicholas storm in North-West Europe and the 2015 St. Agatha storm in the Adriatic and "the hazardous conditions that provided the context for them, are also further reminders of the importance of social science hazards and disaster research for extending our understanding on how human society copes with risks and actual events when they occur" (Perry and Quarantelli, 2005). With climate change and sea-level rise being still a relatively new challenge, experience as to the choice and design of appropriate disaster response measures are still scarce and fragmented in coastal areas. Therefore a better understanding of the interaction amongst cultural values, preferences and possibilities for the implementation of disaster risk reduction measures in a given bio-physical coastal environment is of significant importance if preparedness, adequate responses and the increase of social resilience should be an imminent outcome and an uncontested sustainable goal.

Disaster risk management must be understood as the result of an interconnected ecology where the "physical ecology" is shaped by the "human ecology" (humans and human behaviours that affect or are affected by its physical ecology), which in turn is affected by the rulemaking policies at state, regional, national or international policy institutions. Societal, cultural, economic and political factors, which are intervened with the physical coastal environment, naturally call for integrative and interdisciplinary investigations. Despite such awareness, overcoming the hurdles of understanding and the development of a common vocabulary across disciplines seems to be a significant challenge in interdisciplinary work.

The collection of qualitative data by natural scientists helped to understand knowledge, values and behaviours of stakeholders and to formulate disaster risk reduction measures based on the physical parameters obtained in the two case study sites. Such collaborations have the potential to build bridges amongst the different disciplines. 


\section{Acknowledgements}

This article is supported by the European Commission under the Environment (including climate change) theme of the 7th Framework Programme for Research and Technological Development which funded the project RISC-KIT (grant agreement no: 603458) for which the authors are grateful. Susana Costas is funded through the "FCT Investigator" program (grant no: IF/01047/2014).

We thank Zoitza Kiresiewa, Ecologic Institute, and Lisa Segnestram, Stockholm Environment Institute, for supporting the authors during their research. We further thank Stephen Bell and Lina Röschel (both Ecologic Institute) for proof-reading and Nick Evans and John Tarpey (both Ecologic Institute) for technical support. We also thank the interview partners in the case study sites in Porto Garibaldi and Ria Formosa for openly sharing their perceptions, knowledge and wisdom with us.

\section{References}

Albertazzi, C., Archetti, R., Armaroli, C., Ceroni, M., Ciavola, P., Lamberti, L., Medri, S., 2013. The CoastView Project, Proceedings of Medcoast Conference 7-11 October 2003, Ravenna, Italy, 1, pp. 235-246.

Alexander, D., 2000. Confronting Catastrophe: New Perspectives on Natural Disasters. Oxford University Press, pp. 37-40.

Alexander, D., 2017. Disaster Planning and Emergency Management. http://emergencyplanning.blogspot.de/search?q=1\%

09What+is+essential+reading+in+disaster+studies. (Accessed 30 June 2017).

Allmendinger, J., 2015. Quests for Interdisciplinarity: a Challenge for the ERA and HORIZON 2020, Policy Brief by the Research, Innovation, and Science Policy Experts (RISE). https://ec.europa.eu/research/innovation-union/pdf/expert-groups/rise/ allmendinger-interdisciplinarity.pdf.

Almeida, L.P., Ferreira, Ó., Pacheco, A., 2011. Thresholds for morphological changes on an exposed sandy beach as a function of wave height. Earth Surf. Process. Landforms $36,523-532$.

Almeida, L.P., Vousdoukas, M.V., Ferreira, Ó., Rodrigues, B.A., Matias, A., 2012. Thresholds for storm impacts on an exposed sandy coastal area in southern Portugal Geomorphology 143-144, 3-12.

Armaroli, C., Ciavola, P., Perini, L., Calabrese, L., Lorito, S., Valentini, A., Masina, M. 2012. Critical storm thresholds for significant morphological changes and damage along the Emilia-Romagna coastline, Italy. Geomorphology 143-144, 34-51.

Armaroli, C., Duo, E., 2017. Validation of the coastal storm risk assessment framework along the Emilia-Romagna coast. Coast. Eng. 134, 159-167. https://doi.org/10. 1016/j.coastaleng.2017.08.014.

Basco-Carrera, L., Warren, A., van Beek, E., Jonoski, A., Giardino, A., 2017. Collaborative modelling or participatory modelling? A framework for water resources management. Environ. Model. Softw. 91, 95-110.

Barquet, K., Cumiskey, L., 2017. Using participatory multi-criteria assessments for assessing disaster risk reduction measures. Coast. Eng. 134, 93-102. https://doi.org/ 10.1016/j.coastaleng.2017.08.006.

Bermosa, N., World's Most Famous Renaissance Men or Universal Geniuses, Knoji, https://biographies.knoji.com/worlds-most-famous-renaissance-men-or-universalgeniuses (Accessed 30 June 2017).

Brewer, J., Hunter, A., 1989. Multimethod Research: a Synthesis of Styles. Sage Publications, Newbury Park, Calif.

Bridle, H., Vrieling, A., Cardillo, M., Yoseph, A., Hinojosa, L., 2013. Preparing for an interdisciplinary future: a perspective from early-career researchers. Futures 53, $22-32$.

Bryam, A., 2012. Social Research Methods. Oxford University Press, Oxford.

Ciavola, P., Ferreira, O., Haerens, P., Van Koningsveld, M., Armaroli, C., 2011. Storm impacts along European coastlines. Part 2: lessons learned from the MICORE project. Environ. Sci. Policy 14, 924-933. https://doi.org/10.1016/j.envsci.2011.05.009.

Costas, S., Ferreira, Ó., Martinez, G., 2015. Why do we decide to live with risk at the coast? Ocean Coast. Manag. 118, 1-11.

European Commission, Environment, the EU Floods Directive http://ec.europa.eu/ environment/water/flood_risk (Accessed 19 June 2017).

European Commission, 2017. Environment. http://ec.europa.eu/environment/water/ flood_risk. (Accessed 30 June 2017).

European Union Research Advisory Board, 2004. Interdisciplinary in Research. EURAB04.009-FINAL. http://ec.europa.eu/research/eurab/pdf/eurab_04_009 interdisciplinarity_research_final.pdf.
Eurosion, 2004. Living with Coastal Erosion in Europe: Sediment and Space for Sustainability. Part II - Maps and Statistics. http://www.eurosion.org/project/ eurosion_en.pdf.

Feagin, R.A., Figlus, J., Zinnert, J.C., Sigren, J., Martínez, M.L., Silva, R., Smith, W.K., Cox, D., Young, D.R., Carter, G., 2015. Going with the flow or against the grain? The promise of vegetation for protecting beaches, dunes, and barrier islands from erosion. Front. Ecol. Environ. 13 (4), 203-210.

Freitas, J.G., Dias, J.A., 2013. 1941 windstorm effects on the Portuguese Coast. What lessons for the future? J. Coast. Res. SI65, 714-719.

Garnier, E., Ciavola, P., Spencer, T., Ferreira, Ó., Armaroli, C., McIvor, A., 2017. Historical Analysis of Storm Events: Case Studies in France, England, Portugal and Italy. Coast. Eng. 134, 10-23. http://dx.doi.org/10.1016/j.coastaleng.2017.06.0140378-3839.

González Dávila, O., Stithou, M., Pescaroli, G., Pietrantoni, L., Koundouri, P., DíazSimal, P., Rulleau, B., Touili, N., Hissel, F., Penning-Rowsell, E., 2014. Promoting resilient economies by exploring insurance potential for facing coastal flooding and erosion: evidence from Italy, Spain, France and United Kingdom. Coast. Eng. ISSN: 0378-3839 87, 183-192. https://doi.org/10.1016/j.coastaleng.2013.12.007.

Harley, M.D., Ciavola, P., 2013. Managing local coastal inundation risk using real-time forecasts and artificial dune placements. Coast. Eng. 77, 77-90. http://dx.doi.org/10. 1016/j.coastaleng.2013.02.006.

Harley, M.D., Valentini, A., Armaroli, C., Ciavola, P., Perini, L., Calabrese, L., Marucci, F., 2012. An early warning system for the on-line prediction of coastal storm risk on the Italian coastline. management.77 Coast. Eng. Proc. ISSN: 2156-1028 33. Available at: https://icce-ojs-tamu.tdl.org/icce/index.php/icce/article/view/6702 (M. D.).

Harley, M.D., Valentini, A., Armaroli, C., Perini, L., Calabrese, L., Ciavola, P., 2016. Can an early-warning system help minimize the impacts of coastal storms? A case study of the 2012 Halloween storm, northern Italy. Nat. Hazards Earth Syst. Sci. 16, 209-222.

Klijn, F., Samuels, P., Vanos, A., 2008. Towards flood risk management in the EU: state of affairs with examples from various European countries. Intl. J. River Basin Manag. 6, 307-321.

Marin, V., Palmisani, F., Ivaldi, R., Dursi, R., Fabian, M., 2009. Users' perception analysis for sustainable beach management in Italy. Ocean Coast. Manag. 52, 268-277. http://dx.doi.org/10.1016/j.ocecoaman.2009.02.001.

Martinez, G., 2017. Disaster Risk Reduction Strategies in EU Coastal Areas: Recommendations for EU, National, and Regional Policy Making. http://ecologic.eu/ 14645. (Accessed 30 June 2017).

Martinez, G., Frick, F., Gee, K., 2014. Socioeconomic and cultural issues in the planning, implementation and transfer of adaptation measures to climate change. The example of two communities on the German Baltic Sea Coast. In: Martinez, G., Fröhle, P., Meier, H.J. (Eds.), Social Dimension of Climate Change Adaptation in Coastal Regions, vol. 5. oekom publishing, München, pp. 203-219.

Mileti, D., Noji, E.K., 1999. Disasters by Design. Joseph Henry Press, Washington.

Nones, M., 2015. Implementation of the floods directive in selected EU member states. Water Environ. J. 29, 412-418. http://doi:10.1111/wej.12129.

Nordstrom, K.F., Armaroli, C., Jackson, N.L., Ciavola, P., 2015. Opportunities and constraints for managed retreat on exposed sandy shores: examples from EmiliaRomagna, Italy. Ocean Coast. Manag. ISSN: 0964-5691 104, 11-21. https://doi.org/ 10.1016/j.ocecoaman.2014.11.010.

Perry, R.W., Quarantelli, E. (Eds.), 2005. What is a Disaster? New Answers to Old Questions. Xilibris Press, Philadelphia (vii).

Pescaroli, G., Magni, M., 2015. Flood warnings in coastal areas: how do experience and information influence responses to alert services? Nat. Hazards Earth Syst. Sci. 15, 703-714. http://dx.doi.org/10.5194/nhess-15-703-2015.

Portuguese Environment Agency (2017), https://www.apambiente.pt/index.php? ref $=\mathrm{x} 178$ (Accessed 30 June 2017).

Prati, G., Albanesi, C., Pietrantoni, L., Airoldi, L., 2015. Public perceptions of beach nourishment and conflict management strategies: a case study of Portonovo Bay in the Adriatic Italian Coast. Land Use Policy 50, 422-428. http://dx.doi.org/10.1016/j. landusepol.2015.06.033.

Regione, Emilia-Romagna, 2004. Gestione Integrata Zone Costiere (in Italian). Available at: http://ambiente.regione.emilia-romagna.it/primo-piano/2004/gestioneintegrata-delle-zone-costiere.

Ten Brinke, W., Saeijs, G., Helsloot, I., Alphen, J., 2008. Safety chain approach in risk management. Munic. Eng. 161 (2), 93-102.

Trembanis, A.C., Duo, E., Dohner, S., Grottoli, E., Ciavola, P., 2017. Quick response assessment of the impact of an extreme storm combining aerial drone and RTK GPS. Nat. Hazard Earth Sys. Sci. (under review).

Van Dongeren, A., Ciavola, P., Martinez, G., Viavattene, C., Bogaard, T., Ferreira, O., Higgins, R., McCall, R., 2017. Introduction to RISC-KIT: resilience-increasing strategies for coasts. Coast. Eng. 134, 2-9.

Villatoro, M., Silva, R., Méndez, F.J., Zanuttigh, B., Pan, S., Trifonova, E., Losada, I.J., Izaguirre, C., Simmonds, D., Reeve, D.E., Mendoza, E., Martinelli, L., Formentin, S.M., Galiatsatou, P., Eftimova, P., 2014. An approach to assess flooding and erosion risk for open beaches in a changing climate. Coast. Eng. ISSN: 0378-3839 87, 50-76. https://doi.org/10.1016/j.coastaleng.2013.11.009. 